\title{
Fibrin sheaths in central venous port catheters: treatment with low-dose, single injection of urokinase on an outpatient basis
}

This article was published in the following Dove Press journal:

Therapeutics and Clinical Risk Management

24 January 2017

Number of times this article has been viewed

De-Hua Chang'

Kamal Mammadov'

Tilman Hickethier'

Jan Borggrefe

Martin Hellmich ${ }^{2}$

David Maintz'

Christoph Kabbasch'

'Department of Diagnostic and Interventional Radiology, University Hospital of Cologne, NRW, Germany; ${ }^{2}$ Institute of Medical Statistics, Informatics and Epidemiology, University Hospital of Cologne, NRW, Germany
Correspondence: De-Hua Chang Department of Diagnostic and Interventional Radiology, University Hospital of Cologne, Kerpener Street 62, 50937 Cologne, Germany

Tel +4922I 47882035

Email de-hua.chang@uk-koeln.de
Purpose: Evaluation of the efficacy of single-shot, low-dose urokinase administration for the treatment of port catheter-associated fibrin sheaths.

Methods: Forty-six patients were retrospectively evaluated for 54 episodes of port catheter dysfunction. The presence of a fibrin sheath was detected by angiographic contrast examinations. On an outpatient basis, patients subsequently received thrombolysis consisting of a single injection of urokinase (15.000 IU in $1.5 \mathrm{~mL}$ normal saline) through the port system. A second attempt was made in cases of treatment failure. Patients were followed up for technical success, complications and long-term outcome.

Results: Port dysfunction occurred at a median of 117 days after implantation (range: $7-825$ days). The technical success after first port dysfunction by thrombolysis was $87 \%(40 / 46)$; thereof, initial thrombolysis was effective in $78 \%(36 / 46)$. Nine patients $(20 \%)$ received a second dose of urokinase after previous treatment failure. Follow-up was available for 26 of 40 patients after successful thrombolysis. In 8 of these, rethrombosis occurred after a median of 98 days (range: 21-354 days), whereby rethrombolysis was effective in 5 of 7 (63\%) patients. The overall success of all thrombolyses performed was $70 \%(45 / 64)$. No procedure-related technical or clinical complications occurred. After first favorable thrombolysis, a Kaplan-Meier analysis yielded a 30-, 90- and 180-day probability of patency of $96 \%, 87 \%$ and $81 \%$.

Conclusion: Thrombolytic therapy on an outpatient basis appears to be a safe and efficient. Three-month patency rates are comparable to more invasive treatment options, including catheter exchange over a guide wire and percutaneous fibrin sheath stripping.

Keywords: central venous port catheter, thrombolysis, urokinase, angiography, port dysfunction, catheter occlusion

\section{Introduction}

Central venous port catheters are widely used for the intravenous administration of chemotherapy and parenteral nutrition in patients with oncologic diseases. During the course of usage, catheter-related vein thrombosis, infection and fibrin sheath formation are the most frequent complications. ${ }^{1,2}$ Fibrin sheaths encase the outer wall and the endhole of the catheter, leading to port dysfunction in terms of difficult aspiration and/or high resistance to the injection of fluids. Different approaches to resolve the fibrin sheath have been described, including exchange of the impaired catheter, ${ }^{3}$ the use of a loop snare from a transfemoral venous approach to pull off the sheath from the catheter ${ }^{4,5}$ and thrombolysis. ${ }^{6-9}$ In the latter case, the reported application regimens (single injections vs continuous infusions, local lysis through the catheter vs intravenous systemic application) as well as the thrombolytic agents (streptokinase, urokinase, recombinant 
tissue-type plasminogen activator [rt-PA]) and the dosages administered vary significantly. Overall, all therapies appear to be comparable regarding primary and secondary technical success and complication rates. ${ }^{10,11}$ Therefore, the method of choice should aim to be minimally invasive and cost effective. The purpose of the present study was the evaluation of a noninvasive and uncomplex approach for the treatment of port catheter-associated fibrin sheaths.

\section{Methods}

Our study was approved by the local ethics committee of the medical faculty of the University of Cologne (Registration Number 16-212), which waived the requirement for written informed consent because of the retrospective, observational character of the study. Written informed consent was obtained for publication of the accompanying images. From January 2015 to May 2016, 46 patients (31 female, 15 male; age 56.8, mean \pm 10.5 ; median 59 , range: $24-76$ years) with underlying malignant diseases and port catheter dysfunction due to fibrin sheath formation were referred to our radiology department for evaluation and treatment. Dysfunction of the port was defined as difficulty in blood aspiration and/or high resistance to injection of fluids over the course of ambulatory chemotherapy. Fluoroscopy was used in each case to confirm correct positioning of the catheter tip in the vena cava superior. Subsequently, $5 \mathrm{~mL}$ normal saline solution was slowly injected through the pectoral port chamber. If the flow was preserved, $5 \mathrm{~mL}$ of contrast agent (Accupaque $300 \mathrm{mg} / \mathrm{mL}$; GE Healthcare, Fairfield, CT, USA) was injected in the next step and the run off was depicted using digital subtraction angiography at 2 frames/s. A fibrin sheath was confirmed by presentation of retrograde tracking of a contrast agent along the catheter wall. The length of the fibrin sheath was determined by measuring the distance from the tip to the most proximal exit point of the contrast medium (Figure 1). Patients with associated venous thrombosis, depicted by angiography or ultrasound examination, or a complete intraluminal occluded port system with unfeasible injection were not included in the study. Furthermore, patients with contraindication to thrombolysis, for example, recent gastrointestinal bleeding or stroke, were also excluded from the study.

Thrombolysis was performed by administering a single injection of $15.000 \mathrm{IU}$ urokinase (medac, Wedel, Germany) dissolved in $1.5 \mathrm{~mL}$ normal saline solution through the port chamber. No other treatment-related medication was given. A control angiography was scheduled either 6 hours later or in the morning hours of the next day if patients were referred in the afternoon. The port was flushed with saline

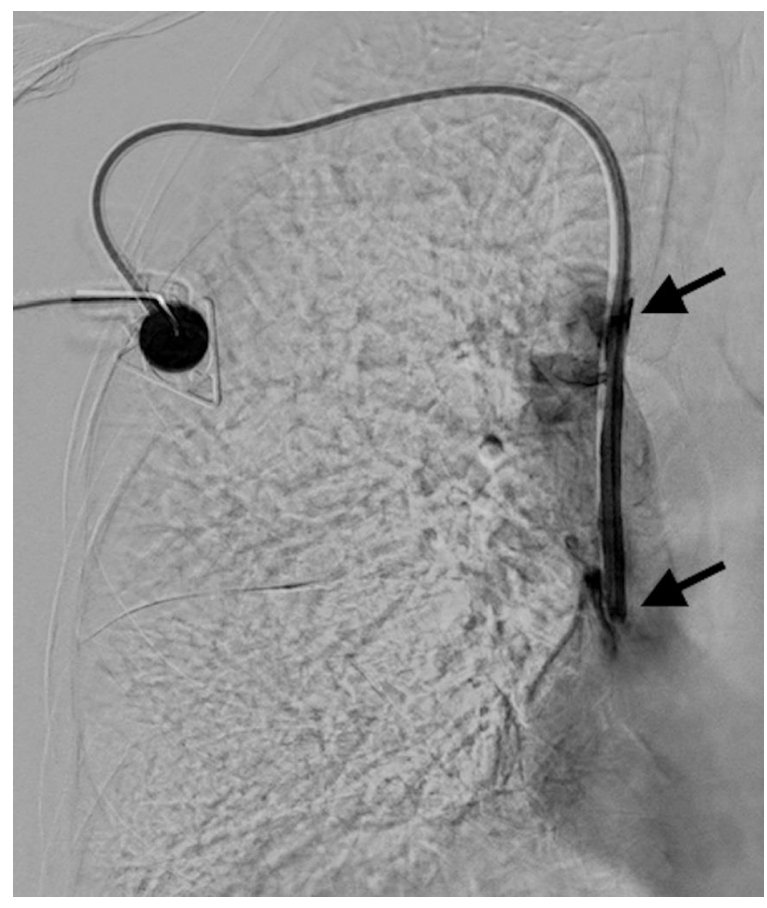

Figure I Digital subtraction angiography of clinically dysfunctional venous port system correctly placed into the cavoatrial junction.

Note: A $7 \mathrm{~cm}$ long fibrin sheath around the tip of the port catheter (arrows) causes an irregular and retrograde opacification along the catheter tube.

and blocked with heparin (500 IU) if the catheter function was restored effortlessly and the patient was discharged from the hospital (Figure 2). In cases of persistent port dysfunction, a second thrombolytic injection was given right after the control angiography with 20.000 IU urokinase dissolved in

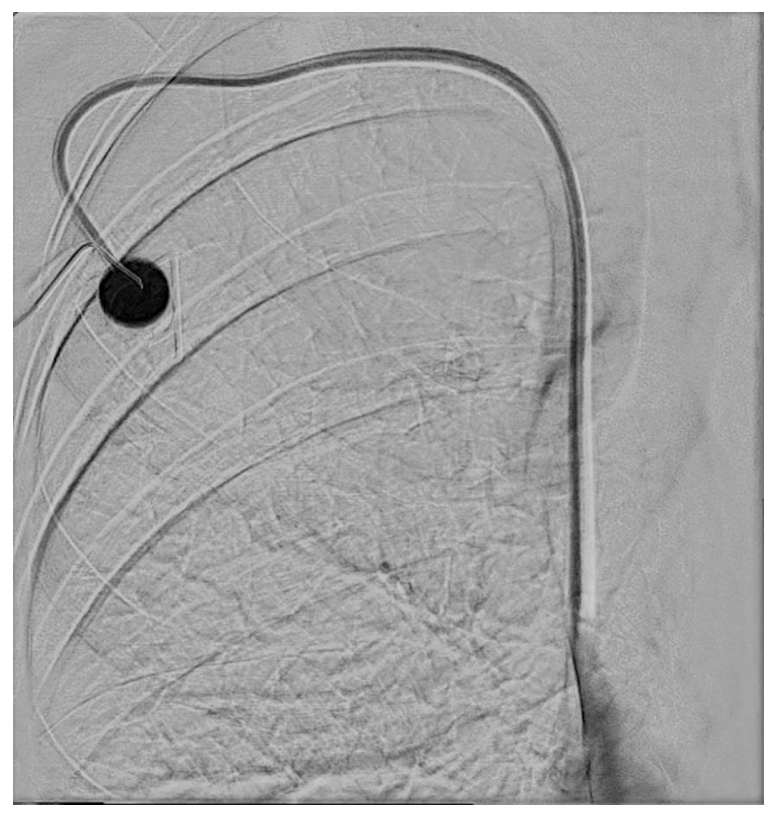

Figure 2 Effective local thrombolysis resulted in complete dissolution of the fibrin sheath.

Note: After contrast injection, there was a regular, jetlike efflux out of the catheter orifice. 
$2 \mathrm{~mL}$ normal saline solution. The follow-up of these patients was the same as described for the initial attempt.

Patients were retrospectively evaluated for primary (success rate after the first attempt), secondary (success rate after the second attempt) and overall (all attempts including rethrombolysis in long-term follow-up) technical success, which was defined as restitution of aspiration and infusion through the port chamber. Procedure-related complications were classified according to the guidelines of the Society of Interventional Radiology. ${ }^{12}$ Catheter patency after initial thrombolysis was extracted from the patients' charts using records from computed tomography staging examinations and ambulatory chemotherapy treatment.

Baseline statistics and survival analysis using KaplanMeier Curves were calculated using Statistical Package for the Social Sciences software (Version 22; IBM Corporation, Armonk, NY, USA). Statistical differences were calculated using the Wilcoxon test. Statistical significance was set at $P<0.05$.

\section{Results}

In all 46 patients, the port was implanted for intravenous chemotherapy of underlying malignant diseases, which were lung cancer $(8 / 46 ; 17 \%)$, gastrointestinal malignancies $(7 / 46 ; 15 \%)$, breast cancer $(6 / 46 ; 13 \%)$, colorectal cancer $(6 / 46 ; 13 \%)$, lymphoma $(6 / 46 ; 13 \%)$, gynecologic cancer $(4 / 46 ; 9 \%)$, malignant melanoma $(4 / 46 ; 9 \%)$ and other reasons $(5 / 46$; $11 \%)$. Port catheters were inserted on the left side in 27 cases (59\%) and on the other side in 19 cases (41\%), each through the subclavian vein.

Patients were referred with either an indication of difficulties in blood aspirating through the port system (22/46 cases [48\%]) or a combination of the former plus resistance to injection of fluids (24/46 cases [52\%]).

Port dysfunction occurred in a range of 7-825 days after implantation (median 117 days). All 46 patients were initially treated with a single injection of $15.000 \mathrm{IU}$ urokinase. Nine of $46(20 \%)$ patients received a second dose due to initial treatment failure. One patient refused a second urokinase injection and underwent port explantation. Clinical and angiographic control after thrombolysis was performed within 5-140 hours after urokinase therapy (median 24 hours). The primary and secondary technical success rates of thrombolysis were $78 \%$ (36/46) and 87\% (40/46), respectively. Repeated thrombolysis after a failed attempt restored aspiration and infusion capabilities in $4 / 9$ patients (44\%). The length of fibrin sheaths (mean \pm standard deviation $[\mathrm{SD}] 4 \pm 2 \mathrm{~cm}$; range: $1-10 \mathrm{~cm}$ ) was not significantly associated with treatment

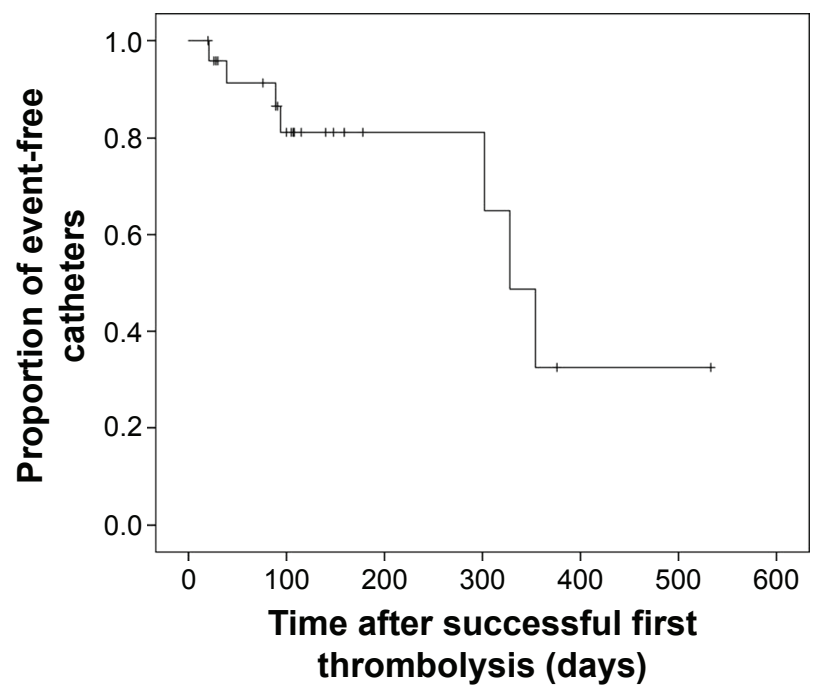

$\begin{array}{lllllll}\begin{array}{l}\text { Number of } \\ \text { catheters }\end{array} & 26 & 14 & 5 & 5 & 1 & 1 \\ & & & & & \end{array}$

at risk

Figure 3 Kaplan-Meier curve showing the distribution of events over time after previous successful first thrombolysis ( $\mathrm{n}=26$ patients); ticks denote censored patients.

failure $(P=0.31)$. There were no major or minor complications related to the procedure.

Follow-up after treatment was available for $30 / 46$ patients (65\%) for a period of 104 days (median) with the range being 7-533 days. After successful treatment, recurrence of fibrin sheath formation and consecutive port dysfunction occurred in $8 / 26$ patients ( $31 \%$ ) after a median of 98 days (range: 21-354 days). Port catheter patency after successful treatment was $96 \%, 87 \%$ and $81 \%$ at 30,90 and 180 days, respectively (Figure 3). The technical success rate of rethrombolysis was $71 \%(5 / 7): 57 \%(4 / 7)$ in the first and 50\% (1/2) in the second attempt. The overall success rate of thrombolyses was $70 \%(45 / 64)$.

Among 8 patients with persistent port dysfunction, 3 patients $(37.5 \%)$ underwent fibrin sheath stripping and 5 patients decided on explantation of the port system. Fibrin sheath stripping was successful in 1 out of 3 patients.

\section{Discussion}

Port catheter dysfunction due to a fibrin sheath formation is a common complication that can occur at any time after implantation. The inability to withdraw blood or to inject fluids is a serious problem that leads to unintended interruption of therapy or ultimately to removal and reinsertion of the catheter if the therapeutic approaches to restore the port function fail. Clinical practice for the treatment of fibrin sheath-associated port dysfunction varies greatly among institutions. These include pulling off the fibrin sheath using 
a snare, catheter exchange over the wire or thrombolytic therapy with different agents and dosages.

Exchanging the catheter and percutaneous snaring of the fibrin sheath are both invasive procedures with additional costs and potentially severe complications such as arrhythmia and pulmonary embolism. ${ }^{13,14}$ In comparison, local thrombolysis through direct injection into the port appears to be atraumatic and very safe. ${ }^{6,15-17}$ There were no minor or major bleeding assigned to local thrombolytic therapy, either in our or in any of the other studies. In a double-blind, placebo-controlled trial, Haire et $\mathrm{al}^{18}$ showed that a low-dose injection of recombinant urokinase (15.000 IU) was more effective than placebo in restoring the patency of occluded central venous access devices and may obviate the need for catheter replacement. Furthermore, long-term follow-up shows no benefit of the invasive procedures compared with thrombolysis, regarding the 3-month patency rates ranging from $37 \%$ to $85 \%$. $3,6,13,19$

Various thrombolytic protocols with different dosages and agents have been implemented for the treatment of fibrin sheath formation. Among these, urokinase and alteplase (tissue plasminogen activator) are most frequently used either as single application into the port catheter or through a peripheral venous access in terms of a prolonged systemic thrombolysis. ${ }^{6}$ The purpose of the present study was to analyze a simple and cost-effective treatment scheme on an outpatient basis. Urokinase was selected as it is well controllable due to quick elimination (half-life period about 10-20 min); also, adverse events such as allergic reactions are less compared to streptokinase. In addition, the current cost of urokinase (50.000 IU) is approximately 5 times less than that of alteplase $(10 \mathrm{mg})$ in our institution.

Furthermore, we decided on a single injection of urokinase instead of a systemic thrombolysis. With this protocol, patients were able to leave the hospital right after the examination. There was no need for close control in the ward or even at an intermediate care unit. For example, Gray et $\mathrm{al}^{11}$ used a urokinase infusion of 60.000 IU/hour, with a total amount of $250.000 \mathrm{IU}$ for the treatment of malfunctioning dialysis catheters. Despite the low dosage and short time of administration used in our study, a comparably high rate of initial technical success was obtained in relation to the more time-consuming infusion protocols with rates ranging from $79.5 \%$ to $97 \% .^{9,11,20}$ There are no definitive guidelines or recommendations of the manufacturer regarding the dosage or volume of urokinase in the treatment of fibrin sheath formation. Deitcher et $\mathrm{al}^{21}$ showed that lower doses of urokinase $(5000 \mathrm{IU} / \mathrm{mL})$ is as effective as higher doses
(15.000 or $25.000 \mathrm{IU} / \mathrm{mL}$ ) with less hemorrhagic risks. However, it must be pointed out that, although there was a significant difference among the treatment groups in the rates of patients experiencing any bleeding complication $(P=0.024)$, only 1 bleeding complication (minor bleeding at a vascular access site) was considered by the investigator to be possibly related to urokinase $(25,000 \mathrm{IU} / \mathrm{mL})$. The dose of urokinase adopted in this study $(10.000 \mathrm{IU} / \mathrm{mL})$ was based on a literature review favoring those at the lower end of the dose range and the empirical experience from our institution. The volume of urokinase used in this study (15.000 IU urokinase in $1.5 \mathrm{~mL}$ ) was just sufficient to ensure infiltration of the catheter-adherent thrombus (port system volume: port chamber $[0.6 \mathrm{~mL}]+$ catheter length $\times 0.02 \mathrm{~mL} / \mathrm{cm} ; 8 \mathrm{~F}$ PowerPort isp MRI; Bard Access Systems Inc., Salt Lake City, UT, USA). A limitation of this study is that the analysis was not randomized and had no reference group. Also, the retrospective study design may have led to a bias in the long-term follow-up evaluation due to incomplete records in the patients' charts.

\section{Conclusion}

In conclusion, low-dose local thrombolysis with urokinase on an outpatient basis proved to be safe and achieved high technical success rates in the treatment of port catheter dysfunction due to fibrin sheath formation. Long-term catheter patency is comparable to other more invasive treatment options, including percutaneous snare maneuver or definitive exchange of the catheter.

\section{Acknowledgment}

This research received no specific grant from any funding agency in the public, commercial or not-for-profit sector. All data will be made available upon request in an anonymized manner.

\section{Disclosure}

The authors report no conflicts of interest in this work.

\section{References}

1. Chang DH, Boecker J, Hellmich M, Krug KB. Experiences with ultrasound guided port impantations via the lateral subclavian vein: a retrospective analysis of 1532 patients. Rofo. 2012;184(8):726-733.

2. Shetty PC, Mody MK, Kastan DJ, et al. Outcome of 350 implanted chest ports placed by interventional radiologists. J Vasc Interv Radiol. 1997;8(6):991-995.

3. Duszak R Jr, Haskal ZJ, Thomas-Hawkins C, et al. Replacement of failing tunneled hemodialysis catheters through pre-existing subcutaneous tunnels: a comparison of catheter function and infection rates for de novo placements and over-the-wire exchanges. $J$ Vasc Interv Radiol. 1998;9(2):321-327. 
4. Johnstone RD, Stewart GA, Akoh JA, Fleet M, Akyol M, Moss JG. Percutaneous fibrin sleeve stripping of failing haemodialysis catheters. Nephrol Dial Transplant. 1999;14(3):688-691.

5. Merport M, Murphy TP, Egglin TK, Dubel GJ. Fibrin sheath stripping versus catheter exchange for the treatment of failed tunneled hemodialysis catheters: randomized clinical trial. J Vasc Interv Radiol. 2000; 11(9):1115-1120.

6. Massmann A, Jagoda P, Kranzhoefer N, Buecker A. Local low-dose thrombolysis for safe and effective treatment of venous port-catheter thrombosis. Ann Surg Oncol. 2015;22(5):1593-1597.

7. Meers C, Toffelmire EB. Urokinase efficacy in the restoration of hemodialysis catheter function. J CANNT. 1998;8(2):17-19.

8. Savader SJ, Haikal LC, Ehrman KO, Porter DJ, Oteham AC. Hemodialysis catheter-associated fibrin sheaths: treatment with a low-dose rt-PA infusion. J Vasc Interv Radiol. 2000;11(9):1131-1136.

9. Whigham CJ, Lindsey JI, Goodman CJ, Fisher RG. Venous port salvage utilizing low dose tPA. Cardiovasc Intervent Radiol. 2002;25(6): 513-516.

10. Janne d'Othée B, Tham JC, Sheiman RG. Restoration of patency in failing tunneled hemodialysis catheters: a comparison of catheter exchange, exchange and balloon disruption of the fibrin sheath, and femoral stripping. J Vasc Interv Radiol. 2006;17(6): 1011-1015.

11. Gray RJ, Levitin A, Buck D, et al. Percutaneous fibrin sheath stripping versus transcatheter urokinase infusion for malfunctioning wellpositioned tunneled central venous dialysis catheters: a prospective, randomized trial. J Vasc Interv Radiol. 2000;11(9):1121-1129.

12. Lewis CA, Allen TE, Burke DR, et al. Quality improvement guidelines for central venous access. J Vasc Interv Radiol. 2003;14(9 Pt 2): 231-235.
13. Crain MR, Mewissen MW, Ostrowski GJ, Paz-Fumagalli R, Beres RA, Wertz RA. Fibrin sleeve stripping for salvage of failing hemodialysis catheters: technique and initial results. Radiology. 1996;198(1):41-44.

14. Winn MP, McDermott VG, Schwab SJ, Conlon PJ. Dialysis catheter 'fibrin-sheath stripping': a cautionary tale! Nephrol Dial Transplant. 1997;12(5):1048-1050.

15. Semba CP, Deitcher SR, Li X, Resnansky L, Tu T, McCluskey ER; Cardiovascular thrombolytic to Open Occluded Lines Investigators. Treatment of occluded central venous catheters with alteplase: results in 1,064 patients. J Vasc Interv Radiol. 2002;13(12):1199-1205.

16. Trerotola SO, Johnson MS, Harris VJ, et al. Outcome of tunneled hemodialysis catheters placed via the right internal jugular vein by interventional radiologists. Radiology. 1997;203(2):489-495.

17. Uldall R, Besley ME, Thomas A, Salter S, Nuezca LA, Vas M. Maintaining the patency of doublelumen silastic jugular catheters for haemodialysis. Int J Artif Organs. 1993;16(1):37-40.

18. Haire WD, Deitcher SR, Mullane KM, et al. Recombinant urokinase for restoration of patency in occluded central venous access devices. A double-blind, placebo-controlled trial. Thromb Haemost. 2004;92(3) 575-582.

19. Brady PS, Spence LD, Levitin A, Mickolich CT, Dolmatch BL. Efficacy of percutaneous fibrin sheath stripping in restoring patency of tunneled hemodialysis catheters. AJR Am J Roentgenol. 1999;173(4): 1023-1027.

20. Lund GB, Trerotola SO, Scheel PF Jr, et al. Outcome of tunneled hemodialysis catheters placed by radiologists. Radiology. 1996;198(2): $467-472$.

21. Deitcher SR, Fraschini G, Himmelfarb J, et al. Dose-ranging trial with a recombinant urokinase (urokinase alfa) for occluded central venous catheters in oncology patients. J Vasc Interv Radiol. 2004;15:575-580.
Therapeutics and Clinical Risk Management

\section{Publish your work in this journal}

Therapeutics and Clinical Risk Management is an international, peerreviewed journal of clinical therapeutics and risk management, focusing on concise rapid reporting of clinical studies in all therapeutic areas, outcomes, safety, and programs for the effective, safe, and sustained use of medicines. This journal is indexed on PubMed Central, CAS,

\section{Dovepress}

EMBase, Scopus and the Elsevier Bibliographic databases. The manuscript management system is completely online and includes a very quick and fair peer-review system, which is all easy to use. Visit http://www.dovepress.com/testimonials.php to read real quotes from published authors. 